\title{
Response to novelty as an indicator of reptile welfare
}

\author{
Sophie A. Moszuti, Anna Wilkinson and Oliver H. P.Burman
}

School of Life Sciences, Joseph Banks Laboratories, Beevor Street University of Lincoln, Lincoln. LN6 7DL. U.K.

Corresponding Author: Anna Wilkinson (awilkinson@lincoln.ac.uk) 
Abstract

Whilst a great deal of research has been focused on identifying ways to assess the welfare of captive mammals and birds, there is comparatively little knowledge on how reptilian species are affected by captivity, and the ways in which their welfare can be accurately assessed. The present study investigated response to novelty - a commonly used approach to assess anxiety-like behaviour and hence welfare in non-human animals - in two species of reptile with the aim of determining whether this approach could be successfully translated from use in mammalian and avian species for use in reptiles, and whether we could also identify reptile-specific and/or species-specific behaviours. Eight red-footed tortoises (Chelonoidis carbonaria) and seventeen bearded dragons (Pogona vitticeps) were observed individually in both familiar and novel environments for 10 minute time periods, and their behaviour recorded. Tortoises were found to begin locomotion sooner when placed in a familiar environment than when placed in a novel environment, they extended their necks further in a familiar environment and their neck length increased over time in both familiar and novel environments, suggesting an overall anxiety-like response to novelty as seen in non-reptilian species. In contrast, whilst bearded dragons exhibited significantly more tongue-touches in a novel, compared to a familiar, environment, they showed no difference between familiar and novel environments in their latency to move. This result suggests that, whilst the dragons appeared to discriminate between the two environments, this discrimination was not necessarily accompanied by an anxiety-like response. This study has confirmed the translatability of response to novelty as an approach to assess anxietylike behaviour in one species of reptile, as well as identifying species-specific behaviours that have the potential to be used in future studies when assessing the welfare of reptiles in response to captive environments, but our results also highlight the need to be aware of species differences within aclass as diverse as reptilia.

Keywords: Reptile behaviour, Response to novelty, Animal welfare. 
Introduction

Despite continued refinement of our ability to assess the welfare of captive animals using behavioural (e.g. optical flow, Dawkins et al. 2012), physiological (e.g. heart rate variability, Rehn \& Keeling 2011) and cognitive indicators (e.g. cognitive bias, Harding et al 2004) in conjunction with the assessment of motivations (e.g. Mason et al. 2001) and preferences (e.g. Nicol et al, 2009), the majority of welfare research has been focused on mammalian and avian species - whether they be laboratory, farm, zoo or companion animals - with comparatively little welfare research carried out on reptiles and/or amphibians. Yet, there has been a recent rapid increase, and continual growth, in the ownership of exotic pets (Whitehead and Forbes, 2013), and it is estimated that of the 11 million ( $40 \%$ of) households in the UK that have pets, around $3 \%$ of these keep reptiles, with estimates of UK captive reptile numbers at c. 0.9 million (0.3 snakes, 0.3 turtles/tortoise, 0.3 lizards) (Pet Food Manufacturing Association, 2016).

These numbers indicate an urgent requirement for the creation of evidence-based guidelines for reptile husbandry and housing to ensure good standards of welfare (Altherr, S. \& Freyer, D. 2001), particularly given that the overall mortality rate for reptiles in the first year following acquisition in UK homes has been estimated from 3.6\% (Robinson et al., 2015) to as high as 75\% (Toland et al. 2012). However, little is known about how captive environments affect reptile welfare or even how welfare in reptilian species should be assessed (Burghardt, 2013). A few studies have shown initial research into reptile welfare (e.g. Kreger \& Mench 1993 (ball python - Python regius, Blue-tongued skink - Tiliqua scincoides), Schuett et al. 2004 (rattlesnakes - Crotalus atrox) Case et al. 2005 (box turtles - Terrapene carolina carolina), Kalliokoski et al. 2012 (green iguanas - Iguana iguana)) and there is literature that highlights the importance of this subject area (Burghardt, 2013; HernandezDivers, 2001; Stanford, 2013; Warwick et al, 2013). Experimental studies have revealed an effect of housing environment on behaviour and immune response, as well as environmental preferences (Case et al. 2005) and impact of handling on behavioural and physiological measures (e.g. Schuett et al. 2004; Langkilde and Shine, 2006; Kalliokoski et al. 2012, although see Kreger \& Mench 1993). But, 
before we can reliably assess the welfare of reptiles in response to the captive environments in which they are housed, further work is required to identify ways in which their welfare can be accurately assessed.

One approach to assess anxiety-like behaviour, and hence welfare, in non-human animals is the investigation of an animal's response when exposed to a novel environment (Langkilde and Shine, 2006).Validated in laboratory rodents using anxiolytic and anxiogenic drug treatments as well as environmental manipulations (i.e. the 'open field test', e.g. Prut \& Belzung, 2003), this approach has been used in a range of species (birds e.g. Coppinger, 1970; mammals e.g. de Passille, et al., 1995; reptiles e.g. Langkilde and Shine, 2006) where observations are made of an animal's response to an environment that may be novel in a number of ways (e.g. size, shape, colour, illumination), with decreasing familiarity with the environment resulting in increased signs of anxiety (File \& Seth 2003). Commonly recorded measures include: latency to move when introduced to the novel environment; total time spent moving around the environment; frequency of defecation/urination; immobility; 'escape' behaviour; self-grooming behaviour, feeding behaviour (if food provided) and heart rate (rats e.g. Jolles, et al., 1979; cows e.g. de Passillé, et al. 1995). The prediction being that individuals exposed to conditions (e.g. drug treatment or housing manipulation) of putatively negative impact will show a more anxiety-like response (e.g. longer latency to move) compared to controls, and vice versa for conditions of putatively positive impact. However, before this approach can be used in reptiles to determine the impact of different conditions (e.g. enclosure size) on their welfare, we first need to understand whether this approach (and those behavioural measures) is also appropriate for use in reptilian species.

The aim of this study was therefore to determine whether the response to novelty approach commonly used to assess the welfare of mammalian and avian species could be successfully translated for use in different reptile species, and whether we could also identify reptile-specific and/or species-specific behaviours. To do this, we compared the behaviour of red-footed tortoises (Chelonoidis carbonaria) and bearded dragons (Pogona vitticeps) when exposed to both a novel and a familiar environment, as 
these species are popular pets and represent two of the four extant reptile orders: Testudines and Squamata.

Methods

\section{Subjects, Housing \& Husbandry}

\section{Tortoises:}

Eight red-footed tortoises were used in this study. They were housed in a group of six and a group of two and their plastron sizes ranged from $7.2 \mathrm{~cm}$ to $15.5 \mathrm{~cm}$. The tortoises were housed in a room maintained at approximately $28^{\circ} \mathrm{C}$ in open topped raised enclosures $(\mathrm{L}=153 \mathrm{~cm}, \mathrm{~W}=92 \mathrm{~cm}, \mathrm{D}=20 \mathrm{~cm})$ with a UV and heat lamp at one end and shelters throughout. The housing contained an orchid bark substrate and slate tile underneath the lights for basking. They had ad libitum access to a waterdish and were fed once a day (fruit and vegetables) with one day a week as a starve day.

\section{Bearded dragons:}

Seventeen adult bearded dragons (Pogona vitticeps), seven males and ten females, were used in this study. They were housed in groups of two or three and ranged in body length (Snout - vent length) from $14.5 \mathrm{~cm}$ to $17.2 \mathrm{~cm}$. They were housed in vivariums with a UV strip bulb along the back wall and a heat lamp at one end. With the room temperature maintained at $27^{\circ} \mathrm{C}$, the vivariums maintained a temperature gradient of approx. $45^{\circ} \mathrm{C}$, directly under the heat lamp, to $27^{\circ} \mathrm{C}$ at the opposite end of the vivarium. Heat lamps were set to turn off for an hour, twice during the day and from $7 \mathrm{pm}-7 \mathrm{am}$. They had sheltered areas and climbing branches within the vivarium, ad libitum access to water and were fed leafy greens once a day and received live food, including locusts and crickets, three time a week.

\section{$\underline{\text { Apparatus }}$}

We used two testing environments that, at the onset of the experiment, were both novel to the animals. They differed from one another in terms of environment shape, floor substrate and wall covering, all selected to provide contrasting contextual cues (e.g. Burman \& Mendl, 1999): (1) Environment 1 - 
The arena was rectangular in shape $(38.25 \mathrm{~cm} \times 120 \mathrm{~cm} \times 31 \mathrm{~cm})$ with a large ' $\mathrm{O}$ ' $(3.5 \mathrm{~cm}$ diameter $)$ on the base that served as a marker on which animals were initially positioned. There was a bubble wrap flooring substrate and an animal print wall covering. This testing environment was set up on the floor; (2) Environment 2 - The arena was almost square in shape $(77 \mathrm{~cm} \times 80.5 \mathrm{~cm} \times 31 \mathrm{~cm})$ with a large ' $\mathrm{X}$ ' $(3.5 \mathrm{~cm}$ square) on the base that served as a marker on which animals were initially positioned. There was a sawdust flooring substrate and a decorative wrapping paper wall covering. This testing environment was set up on a table $72.5 \mathrm{~cm}$ off the ground. Tripods and cameras were set up approximately $90 \mathrm{~cm}$ above the environments and at the centre of the arena sides, closest to the start marker, at a height of $35 \mathrm{~cm}$ to observe the animals from different positions. All aspects were the same for both species except that a fine black fibreglass mesh was secured over the top of both arenas when testing the bearded dragons to prevent the possibility of escape.

\section{Experimental procedure}

\section{Habituation trials}

Animals were assigned to groups pseudo-randomly to match for age, as response to novelty changes over age in some species (Casadesus, et al., 2001), as well as matching for experience to housing, previous experimental experience and conspecifics.

Half of the subjects (group 1) were habituated to environment 1 and the other half (group 2) to environment 2, making these their 'familiar' environments. A habituation trial involved an animal being picked up out of a travel container and individually placed into the allocated environment on the marker and allowed to move freely around for a period of 10 minutes per day for four consecutive days. Trials took place at the same time each day for individual subjects. Following their 10 minute exposure to the environment, animals were returned to their home enclosures. The environments were cleaned before each trial in order to prevent any olfactory cues influencing behaviour. This required the sawdust substrate to be mixed around and re-laid and the bubble wrap substrate to be wiped over using a diluted disinfectant cleaner (safe4). This method has shown to be effective in other studies (Wilkinson, et al. 2010). This habituation process was carried out for both tortoises and bearded 
dragons. After experiencing the four habituation trials that allowed familiarisation to one of the two environments, the animals received two test trials.

\section{Test trials}

On Test day 1, half of the animals from each group, selected at random, were tested in the same familiar environment in which they already had been habituated, whereas the remainder were tested in the other, novel, environment with which they had no previous experience. For Test day 2 , those individuals that had initially been tested in the familiar environment were tested in the novel environment, whilst those that had first been tested in the novel environment were returned to their familiar environment for the second test (see Figure 1). Thus, all individuals were tested once in both a familiar and a novel environment, balanced for order of exposure (i.e. half the animals experienced the novel (Test day 1) and then the familiar environment (Test day 2) and vice versa) and environmental context (i.e. for half of the animals Environment 1 was familiar and Environment 2 novel, for the remainder, Environment 1 was novel and Environment 2 familiar). Animals were transferred to the assigned environment via a secure travel container and were picked up and placed on the marker to be observed for a period of 10 minutes. At the end of the observation period, animals were then picked up and transferred back into their home enclosure. The environments were cleaned before every trial, as previously described.

\section{* Figure One *}

\section{Behavioural measures}

In addition to recording the typically used avian/mammalian behavioural measures of response to novelty during each $10 \mathrm{~min}$ trial, such as latency to move, duration of locomotion, and frequency of urination and faecal deposits (Cowan, 1977; de Passillé, et al. 1995; Jolles, et al. 1979), we recorded novel reptile-specific measures such as neck and head extension (at 60 second intervals throughout the test trial (tortoises only)) as well as tongue-flicks directed into the air (air-flicks) and tongue-flicks making direct contact with a surface (tongue-touches) (bearded dragons only). Neck/head extension in 
tortoises was recorded as the distance $(\mathrm{cm})$ of the tip of the noise from the front of the carapace. This measurement was calculated using image J (@1997-2016 Rasband, W. S.) software in which video recordings were uploaded and viewed; the software used known measurements, in this case shell length, in order to calculate the neck/head extension. Tongue-flicking describes the dragon opening its mouth and extending its tongue, sometimes several times in succession, with the tongue visible for about $0.5 \mathrm{sec}$ for each extension. When the tongue-flicking occurred in direct contact with an object (e.g. environment wall or floor) then this was recorded to as 'tongue-touches', but when there was no clear tongue-focus it was recorded as 'air-flicks'. These behaviours were selected based on our own preliminary observations of these species and their response to routine husbandry changes, in conjunction with literature that defines tongue-flicking behaviour.

\section{Data analysis}

Behaviours were extracted from each ten minute video observation using Solomon coder software (2006-2011 András Péter). According to whether or not the data met the assumptions (e.g. normality) for parametric testing, the data was then assessed for statistical significance (SPSS version 21) using either Wilcoxon signed rank tests (e.g. to compare the average latency before moving, between familiar and novel environments) or a repeated measures General Linear Model (e.g. for average neck length of tortoises) when Time (0-600secs divided into 11 intervals of 60sec) was included as an additional within-subjects factor alongside Treatment (familiar/novel environment). Statistical tests were two-way and the accepted significance threshold was $\mathrm{p} \leq 0.05$.

Results

\section{$\underline{\text { Tortoises }}$}

There was no significant difference in the total time tortoises spent moving in the novel and familiar environments $(Z=0.140, N=8, p=0.889)$ (see Figure 2(a)). However, tortoises were significantly quicker to begin locomotion after being placed in a familiar environment in comparison to when 
placed into a novel environment $(\mathrm{Z}=1.960, \mathrm{~N}=8, \mathrm{p}=0.05)$ (see Figure 2(b)). The results revealed tortoises extended their necks more in the familiar environment compared to the novel environment (see Figure 2(c)) after observing an overall effect of treatment $(\mathrm{F} 1,7=39.241, \mathrm{p}<0.001)$ on neck extension. Also regardless of the environment in which they were placed, tortoises increased the extension of their neck after the initial 60secs (post-hoc pairwise comparison with Bonferroni adjustment: 0 vs. $60 \sec (\mathrm{p}=0.289) ; 0$ vs. $120 \mathrm{sec}(\mathrm{p}=0.028) ; 0$ vs. $180 \mathrm{sec}(\mathrm{p}=0.053) ; 0$ vs. $240 \sec (\mathrm{p}$ $=0.005) ; 0$ vs. $300 \sec (\mathrm{p}=1.00) ; 0$ vs. $360 \sec (\mathrm{p}=0.05) ; 0$ vs. $420 \sec (\mathrm{p}=0.041) ; 0$ vs. $480 \sec (\mathrm{p}=$ $0.014) ; 0$ vs. $540 \mathrm{sec}(\mathrm{p}=0.001) ; 0$ vs. $600 \mathrm{sec}(\mathrm{p}=0.007)$, all other comparisons $\mathrm{p}>0.05)$ (see Figure 2(d)); showing a significant effect of time on neck length $(F 10,70=5.867, p<0.001)$. There was no significant interaction between treatment and time $\left(\mathrm{F}_{10,70}=0.809, \mathrm{p}=0.621\right)$. Defecation and urination did not occur sufficiently frequently to be analysed.

* Figure Two *

\section{Bearded Dragons}

There was no significant difference in the total time spent moving in the two environments $(Z=1.491$. $\mathrm{N}=17, \mathrm{p}=0.136$ ) (see Figure 3(a)) or on the latency to begin locomotion in the familiar and novel environments $(Z=0.450, N=17, p=0.653$ ) (see Figure 3(b)), and no faecal deposits occurred in either condition. When assessing tongue-flicking behaviour, we found a significant difference in the frequency of tongue-touches between the environments $(Z=2.207, N=17, p=0.027)$, showing that bearded dragons exhibited significantly more tongue-touches in the novel environment. However, there was no significant difference in the frequency of air-flicks between the familiar and novel environments $(Z=1.490, N=17, p=0.136)$ (see Figure 3(c)).

\footnotetext{
* Figure Three *
}

Discussion 
Our results have enabled us to determine that response to novelty, an approach developed in mammalian and avian species to assess anxiety-like behaviour, is translatable to at least one species of reptile. We have also identified new species-specific behavioural responses to novelty (i.e. neck extension in tortoises and tongue-flicking on a surface (tongue-touches) and sampling the air (airflicks) in bearded dragons), with both the reptile species studied here showing significant differences in their behaviour in response to a novel environment. Red-footed tortoises, as with mammalian and avian species, demonstrated a longer latency to locomotion in a novel environment, and also showed differences in their amount of neck extension, extending their necks further with increasing familiarity. Whereas bearded dragons, although they failed to show an influence of novelty on locomotion, did increase tongue-touches in a novel environment. As well as confirming that some of the existing mammalian and avian behavioural responses to novelty (e.g. latency to locomotion) are translatable to some reptilian species, we have identified, for the first time in this context, novel species-specific behaviours for two species of reptile (i.e. neck extension in tortoises and tongueflicks (tongue-touches and air-flicks) in bearded dragons) that could mean increased future test efficacy.

Changes in patterns of behaviour are considered to characterise an animal's first level of response to a stressful or aversive environment (Temple, et al. 2011) as well as changes in physiological measures such as blood stress hormone concentration when exposed to a novel environment (e.g. Lizards Langkilde and Shine 2006). Evidence of fluctuations in activity levels and exploratory/locomotory behaviour has been observed in a number of studies (e.g. Salak-Johnson et al. 2004; Carlstead, et al. 1993; Romeyer and Bouissou, 1992) that show suppression of exploratory behaviour in 'stressor' conditions and longer latencies to enter a test room containing a novel object, suggesting anxiety. Boissy and Bouissou (1995) observed the behavioural reactions of heifers in an open field test and suggested that levels of inactivity and latency to enter and exit the test set up could be interpreted as an expression of fear in cattle when correlated with fear-related reactions previously identified in their other tests (i.e. response to a novel object, food placed in an unfamiliar environment and a surprise effect). These reported longer latencies to enter test set-ups as an indication of fear in domestic cattle 
can be related to our own findings, with tortoises showing a significantly longer latency to begin locomotion when exposed to a novel environment. In particular, pre-exposure to a novel environment can result in reduced latency to enter a novel environment (Blanchard et al. 1974), and this change in response with increasing familiarity/decreasing novelty suggests a clear relationship with anxiety. This is also supported by the results of Langkilde's and Shine's (2006) study which showed elevated stress hormone in a lizard when exposed to a novel environment. These findings support the interpretation of our results and suggest that the behavioural responses we have observed indicate anxiety in tortoises and, in turn, link with our observations of neck length as a further possible measure of affective state and hence welfare. However, from our findings the same interpretation of behaviour may not be valid for bearded dragons, as no effect of novelty on latency to begin locomotor behaviour was found, suggesting that, although they perceived the novelty of the environment (as indicated by an increase in tongue-touches), this response may not be related to anxiety. Response to novelty has also served as a method to examine the impact of incubation temperature on the behaviour of lizards in which they showed no significant effect of novelty on locomotory behaviour (Siviter, et al. 2016). This difference between the two species suggests that there are likely to be different measures needed to assess the welfare of different reptile species, and this is unsurprising given the large variation in behaviour, physiology and anatomy between different species of reptile.

We found a significant effect of novelty and time on tortoise neck extension, with more extension in a familiar environment and increased extension over time - regardless of environment - both results suggesting that neck extension could be an indicator of anxiety, as tortoises extended their necks further as their apparent anxiety diminished (i.e. as familiarity increased). Neck extension and retraction has been observed in surprisingly few studies although it has been suggested that tortoises will retract into their shell when startled, which is often an avoidance response to a possible threat or stressor. For instance, Pike et al. (2005) observed that tortoises that experienced frequent handling often resisted by kicking and hissing and, on release, would remain retracted in their shell for some time before retreating into a burrow. This would suggest that retracting into their shells is a response 
of anxiety and an avoidance or defense behavior in response to a potential threat, and that neck extension, in contrast, relates to a more relaxed state. Neck extension in tortoises may therefore be a valuable indicator of anxiety for future studies of tortoise welfare - although clearly more workis required in this area.

Bearded dragons were found to exhibit tongue-touches significantly more frequently in a novel condition than in a familiar one. Tongue-flicking behaviour is characteristic to squamate reptiles and allows them to identify prey and mediate social responses (Halpern, 1992; Burghardt, 1966, 1967, 1968) by sampling both volatile and non-volatile chemicals from their environment (Cooper, 1994) which enter into the vomeronasal system (tongue and vomeronasal/Jacobson's organ) (Schwenk, 1995). As in snakes and monitor lizards, bearded dragons flick their tongue out of the mouth to collect chemical particles from the environment (Divers and Mader, 2005). A number of studies by Aragón, et al. (2000, 2001) show Lacerta monticola express differential rates of tongue-flicking when discriminating odours of unfamiliar and familiar conspecifics. One study showed significant differences in the total amount of tongue-flicking among the familiar and unfamiliarconditions; lizards displayed a significantly higher rate of tongue-flicking in the presence of an unfamiliar olfactory stimulus than a familiar one (Aragón, et al., 2000). A later study showed that the same species express significantly higher levels of escape behaviour in response to unfamiliar odours suggesting they want to avoid potential aggressive interactions (Aragón, et al. 2003). Although this might be taken to suggest that the elevated levels of the tongue -ouch observed in the current study were due to the dragons assessing their surroundings for potential threat, it is perhaps more parsimonious to interpret this change as a chemosensory investigation in response to a novel environment, without assuming a concomitant change in affective state. This reveals the difficulty with interpreting behaviour in such a diverse range of species where so little research has been carried out.

To summarise, there is currently limited information available concerning reptile husbandry and welfare, and the knowledge of specific species requirements is extremely limited (Warwick, et al. 
1995). This gap in knowledge only highlights the importance of developing this area of research (Warwick, et al. 1995) in order to accommodate for the increasing number of reptiles kept as pets of in captive collections. Our research has confirmed response to novelty as an approach to assess affective state, and hence welfare, that translates to a reptilian species (the red-footed tortoise), as well as identifying a novel behaviour (neck extension) that could be used in the future for assessing anxiety in this species. Future research looking at other measures (e.g. stress hormone levels in urine and faeces) will aid in identifying the level of stress caused by a novel environment, therefore furthering our current findings and degree of knowledge in relation to reptile husbandry and welfare. However, given the species differences observed here, much more research investigating the generalizability of this approach to other species of reptile, as well as the development of additional accurate measures of welfare, is essential in order to start to gain an understanding of appropriate measures of assessing reptile welfare. 


\section{Acknowledgements}

We would like to thank the cold-blooded cognition group for their help throughout the project. We also thank Dawn Simpson and Emma Huntbach for caring for the animals.

The authors declare no competing financial interests

The research was approved by the University of Lincoln's ethics committee 


\section{References}

Altherr, S. \& Freyer, D. 2001. Mortality and morbidity in private husbandry of reptiles. RSPCA, UK.

Aragón, P., López, P. \& Martín, J. 2000. Size-dependent chemosensory responses to familiar and unfamiliar conspecific faecal pellets by the Iberian rock-lizard (Lacerta monticola). Ethology. Vol. 1062), pp. 1115-1128.

Aragón, P., López, P. \& Martín, J. 2001. Discrimination of femoral gland secretions from familiar and unfamiliar conspecifics by male Iberian rock-lizards, Lacerta monticola. Journal of Herpetology. Vol. 35 2), pp. 346-350.

Aragón, P., López, P. \& Martín, J. 2003. Differential avoidance responses to chemical cues from familiar and unfamiliar conspecifics by male Iberian rock lizards (Lacerta monticola). Journal of Herpetology. Vol. 37 (3), pp. 583-585.

Archer, J. 1975. Rodent sex differences in emotional and related behaviour 1. Behavioural Biology. Vol. 14 (4), pp. 451-479.

Blanchard, R.J., Kelley, M.J. \& Blanchard, D.C. 1974. Defensive reaction and exploratory behaviour in rats. Journal of Comparative and Physiological Psychology. Vol.8 (6), pp. 1129-1133.

Boissy, A. and Bouissou, M.F., 1995. Assessment of individual differences in behavioural reactions of heifers exposed to various fear-eliciting situations. Applied animal behaviour science, 46(1-2), pp.17-31.

Burghardt, G.M., 1966. Stimulus control of the prey attack response in naive garter snakes. Psychonomic Science, 4(1), pp.37-38.

Burghardt, G.M., 1967. Chemical perception in newborn snakes. Psychology Today, 1(4), p.51.

Burghardt, G.M., 1968. Chemical preference studies on newborn snakes of three sympatric species of Natrix. Copeia, pp.732-737.

Burghardt, G.M. 2013. Environmental enrichment and cognitive complexities in reptiles and amphibians: Concepts, review and implications for captive populations. Applied Animal Behaviour Science. Vol. 147 (3-4), pp. 286-298.

Burman, O. \& Mendl, M. 1999. The effects of environmental context on laboratory rat social recognition. Animal Behaviour. Vol. 58, pp. 629-634.

Carlstead, K., Brown, J.L. \& Strawn, W. 1993. Behavioural and physiological correlates of stress in laboratory cats. Applied Animal Behaviour Science. Vol. 38 (2), pp. 143-158. 
Casadesus, G., Shukitt-Hale, B. and Joseph, J.A., 2001. Automated measurement of age-related changes in the locomotor response to environmental novelty and home-cage activity. Mechanisms of ageing and development, 122(15), pp.1887-1897.

Case, B.C., Lewbart, G.A. \& Doerr, P.D. 2005. The physiological and behavioural impacts of and preference for an enriched environment in the eastern box turtle (Terrapene carolina carolina). Applied Animal Behaviour Science. Vol. 92, pp. 353-365.

Cooper, W.E. 1994. Chemical discrimination by tongue-flicking in lizards: A review with hypotheses on its origin and its ecological and phylogenetic relationships. Journal of Chemical Ecology. Vol. 20 (2), pp. 439-487.

Cowan, P.E. 1977. Neophobia and neohphilia: New-object and new-place reactions of three Rattus species. Journal of Comparative and Physiological Psychology. Vol. 91 (1), pp. 63-71.

Dawkins, M.S., Cain, R, \& Roberts, S.J. 2012. Optic flow, flock behaviour and chicken welfare. Animal Behaviour. Vol. 4(1), pp. 219-223.

De Passillé, A., Rushen, J. \& Martin, F. 1995. Interpreting the behaviour of calves in an open-field test: a factor analysis. Applied Animal Behaviour Science. Vol. 45 (3), pp. 201-213.

Divers, S.J. \& Mader, D.R. 2005. Reptile Medicine and Surgery. Elsevier Health Sciences, Canada.

File, S.E. \& Seth, P. 2003. A review of 25 years of the social interaction test. European journal of pharmacology. Vol. 463, pp.35-53.

Gray, J.A. \& Lalljee, B. 1974. Sex differences in emotional behaviour in the rat: Correlation between open-field defecation and active avoidance. Animal Behaviour. Vol. 22, pp. 856-861.

Halpern, M. 1992. Nasal Chemical Senses in Reptiles: Structure and Function. In: Gans, C., Crews, D. (ed.) Hormones, Brain and Behaviour. Biology of the Reptilia Series. Vol. 18. Chicago: University of Chicago Press pp. 424-524.

Harding, E.J., Paul, E.S. \& Mendl, M. 2004. Animal Behaviour: Cognitive bias and affective state. Nature. Vol. 427, pp. 312.

Hernandez-Divers, S.J. 2001. Clinical aspects of reptile behaviour. The Veterinary Clinics of North America. Exotic Animal Practice. Vol. 4 (3), pp. 599-612.

Jolles, J., Rompa-Barendregt, J. \& Gispen, W.H. 1979. Novelty and grooming behaviour in the rat. Behavioral and Neural Biology. Vol. 25 (4), pp. 563-572.

Kalliokoski, O., Timm, J.A., Ibsen, I.B. Hau, J., Frederkiksen, A-M., B. \& Bertelsen, M.F. 2012. Fecal glucocorticoid response to environmental stressors in green iguanas (Iguana iguana). General and Comparative Endocrinology. Vol. 177, pp. 93-97. 
Kreger, M.D. \& Mench, J.A. 1993. Physiological and behavioral effects of handling and restraint in the ball python (Python regius) and the blue-tongued skink (Tiliqua scincoides). Applied Animal Behaviour Science. Vol. 38, pp. 323-336.

Langkilde, T. and Shine, R., 2006. How much stress do researchers inflict on their study animals? A case study using a scincid lizard, Eulamprus heatwolei. Journal of Experimental Biology, 209(6), pp.1035-1043.

Mason, G.J., Cooper, J. \& Clarebrough, C. 2001. Frustrations of fur-farmed mink. Nature. Vol. 410, pp. 35-36.

Nicol, C.J., Caplen, G., Edgar, J. \& Browne, B. 2009. Associations between welfare indicators and environmental choice in laying hens. Animal Behaviour. Vol. 78, pp. 413-424.

Pet Food Manufacturing Association (2016) Pet Population Report. PFMA, London, U.K.

Pike, D.A., Dinsmore, A., Crabill, T., Smith, R.B. \& Seigel, R.A. 2005. Short-term effects of handling and permanently marking gopher tortoises (Gopherus Polyphemus) on recapture rates and behaviour. Applied Herpetology. Vol. 2, pp. 139-147.

Prut, L. \& Belzung, C. 2003. The open field as a paradigm to measure the effects of drugs on anxietylike behaviors: a review. European journal of pharmacology, 463(1), pp.3-33.

Rasband, W.S., ImageJ, U. S. National Institutes of Health, Bethesda, Maryland, USA, https://imagej.nih.gov/ij/, 1997-2016.

Rehn, T. \& Keeling, L.J. 2011. The effect of time left alone at home on dog welfare. Applied Animal Behaviour Science. Vol. 129, pp. 129-135.

Robinson, J.E., St. John, F.A.V., Griffiths, R.A. \& Roberts, D.L. 2015. Captive Reptile Mortality Rates in the Home and Implications for the Wildlife Trade. PLoS ONE. Vol. 10(11), e0141460.

Romeyer, A. \& Bouissou, M-F. 1992. Assessment of fear reactions in domestic sheep andinfluences of breed and rearing conditions. Applied Animal Behaviour Science. Vol. 34, pp. 93-119.

Salak-Johnson, J.L., Anderson, D.L. \& McGlone, J.J. 2004. Differential dose effects of central CRF and effects of CRF astressin on pig behaviour. Physiology \& Behavior. Vol. 83 (1), pp. 143 -150.

Schuett, G.W., Taylor, E.N., Van Kirk, E.A. \& Murdoch, W.J. 2004. Handling Stress and Plasma Corticosterone Levels in Captive Male Western Diamond-backed Rattlesnakes (Crotalus atrox). Herpetological Review. Vol. 35(3), pp. 229-233.

Schwenk, K., 1995. Of tongues and noses: chemoreception in lizards and snakes. Trends in ecology \& evolution, Vol. 10(1), pp.7-12.

Siviter, H., Deeming, D.C., Rosenberger, J., Burman, O.H., Moszuti, S.A. and Wilkinson, A., 2016. The impact of egg incubation temperature on the personality of oviparous reptiles. Animal Cognition, pp.1-8. 
Stanford, M. 2013. Keeping exotic pets. The Veterinary Record. Vol. 173 (23), pp. 586.

Temple, D., Manteca, X., Velarde, A. \& Dalmau, A. 2011. Assessment of animal welfare through behavioural parameters in Iberian pigs in intensive and extensive conditions. Applied Animal Behaviour Science. Vol. 131, pp. 29-39.

Toland E., Warwick C. \& Arena P. 2012. The exotic pet trade: pet hate. Biologist, Vol. 59, pp. 14-8.

Warwick, C., Frye, F.L. \& Murphy, J.B. 1995. Health and Welfare of Captive reptiles. Springer, Netherlands.

Warwick, C., Environment, P., Lindley, S., Jessop, M. \& Steedman, C. 2013. Assessing reptile welfare using behavioural criteria. In Practice. Vol. 35, pp. 123-131.

Whitehead, M. \& Forbes, N. 2013. Keeping exotic pets. The Veterinary Record. Vol. 173 (22), pp. 558.

Wilkinson, A., Kuenstner, K., Mueller, J. and Huber, L., 2010. Social learning in a non-social reptile (Geochelone carbonaria). Biology Letters, p.rsbl20100092. 
Figure One:

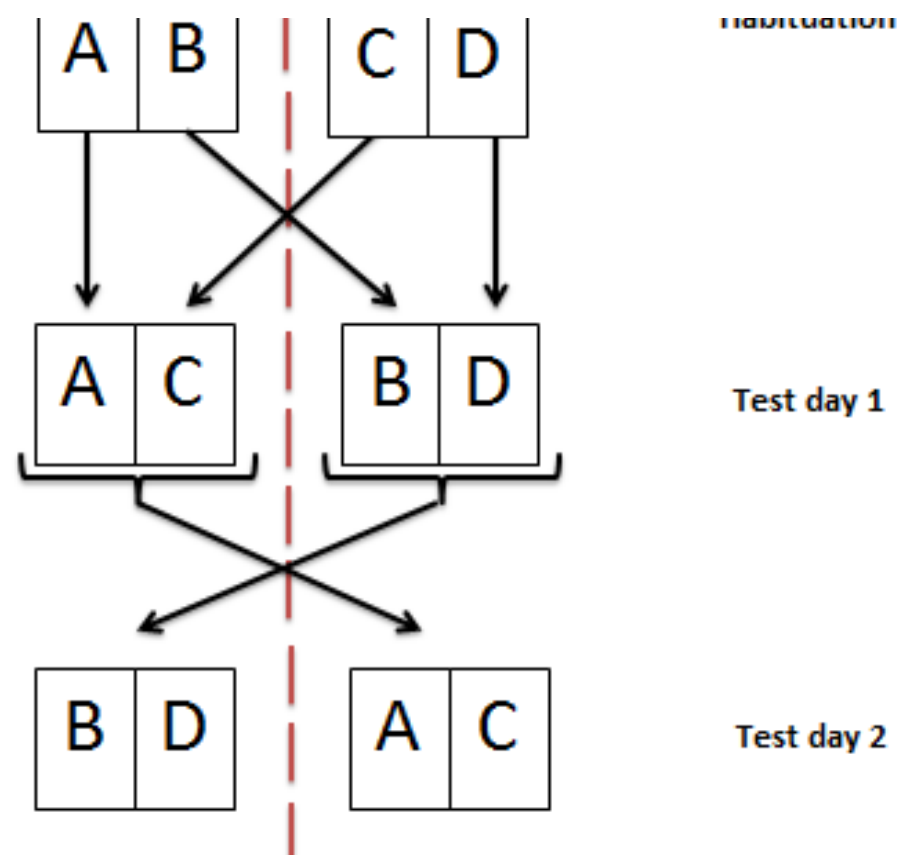


Figure Two:
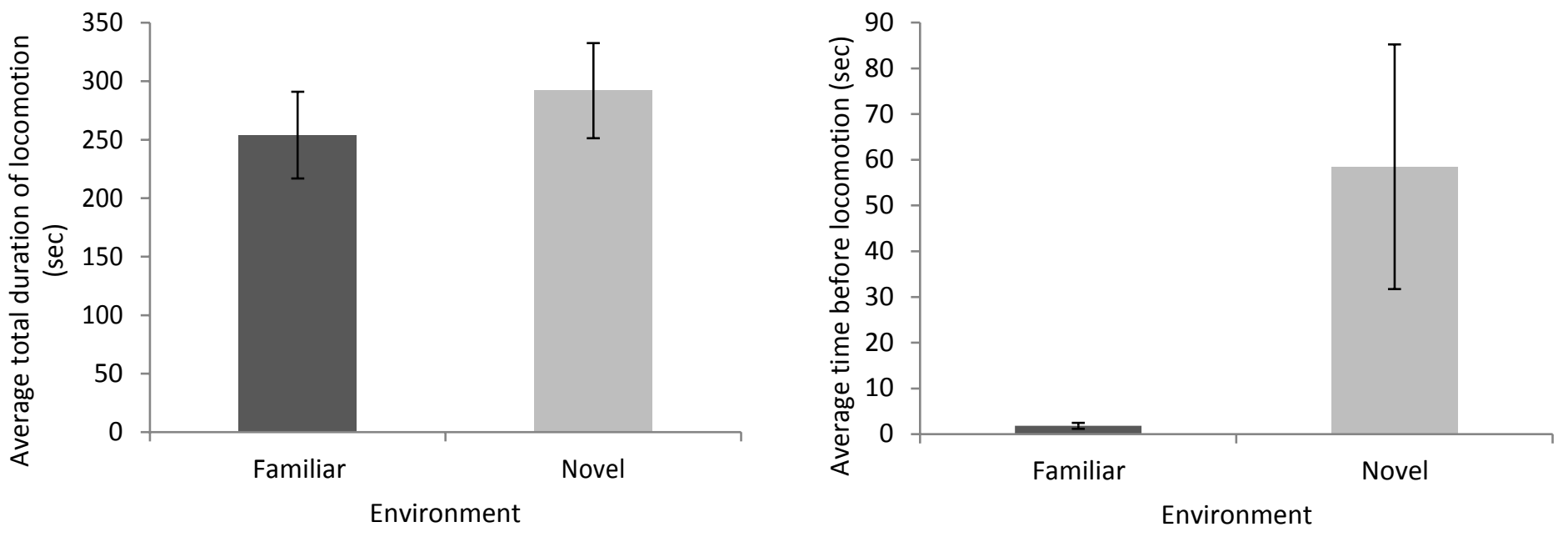

(a)

(b)

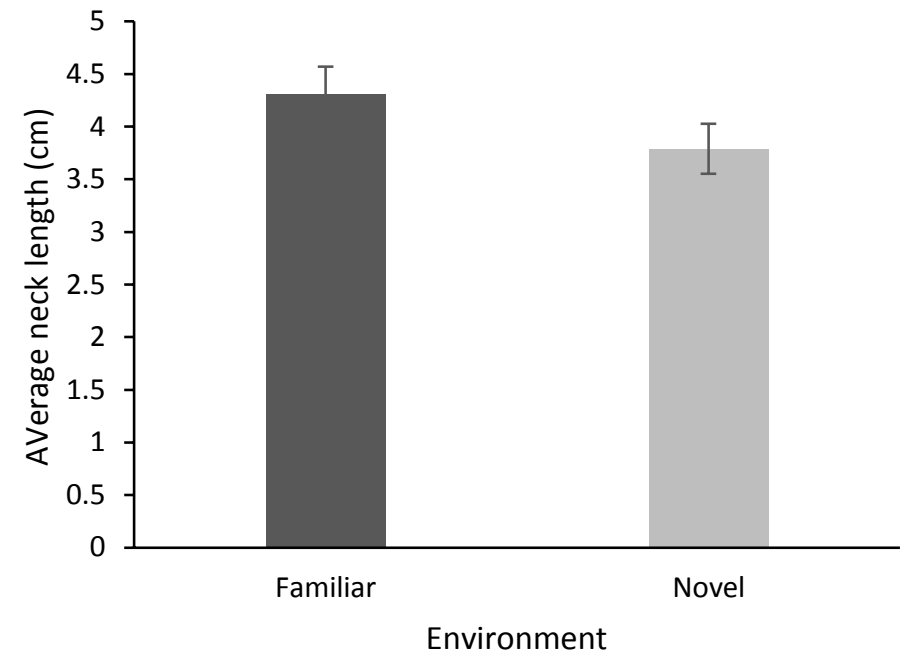

(c)

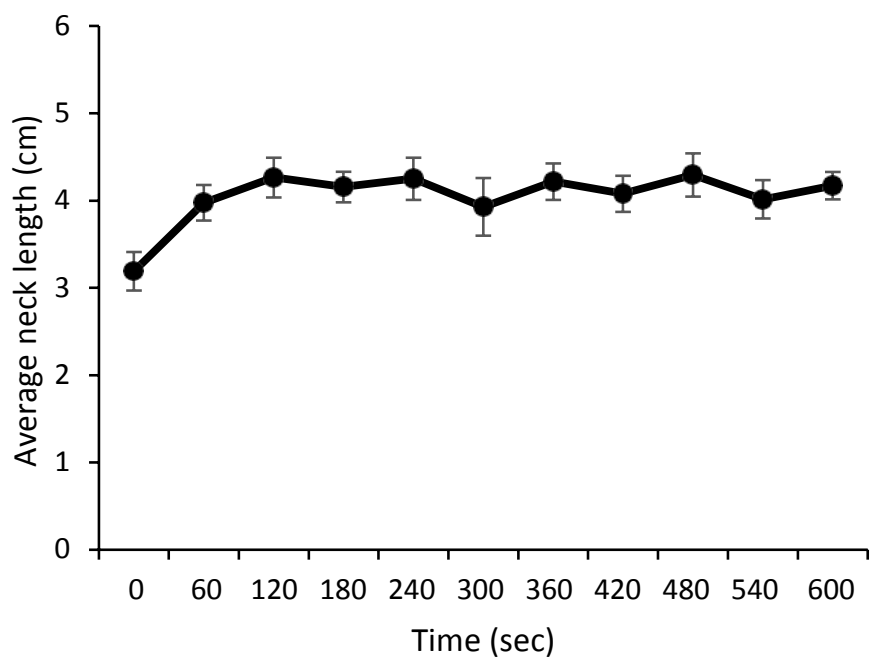

(d) 
Figure Three:
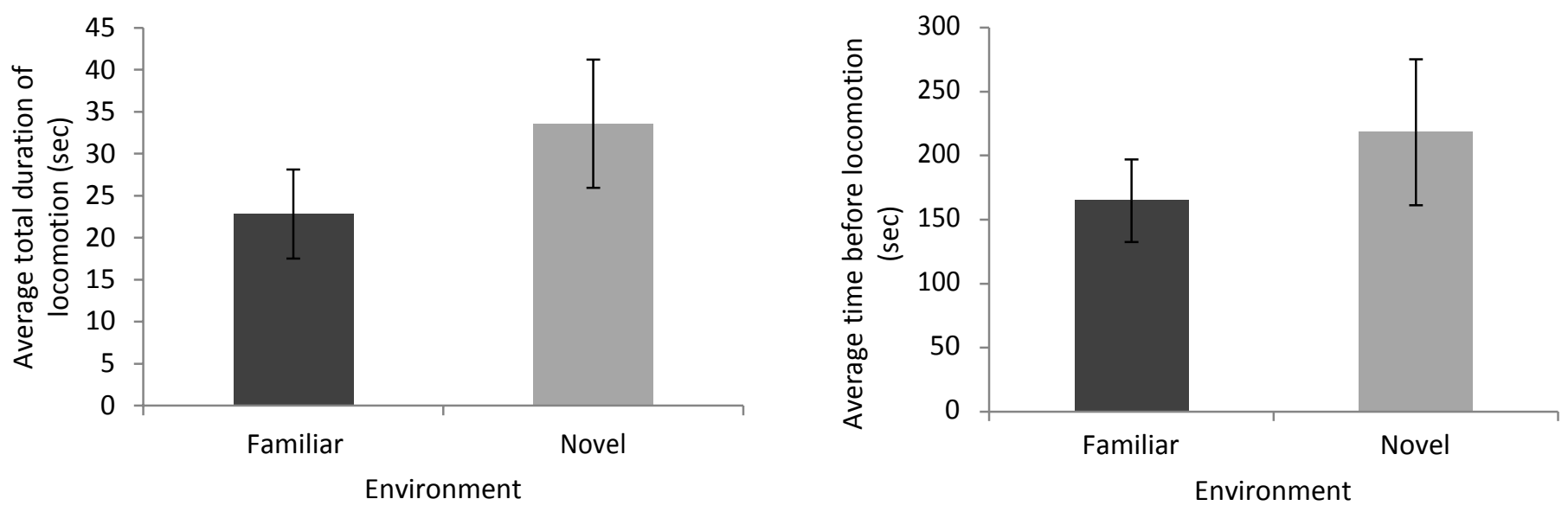

(a)

(b)

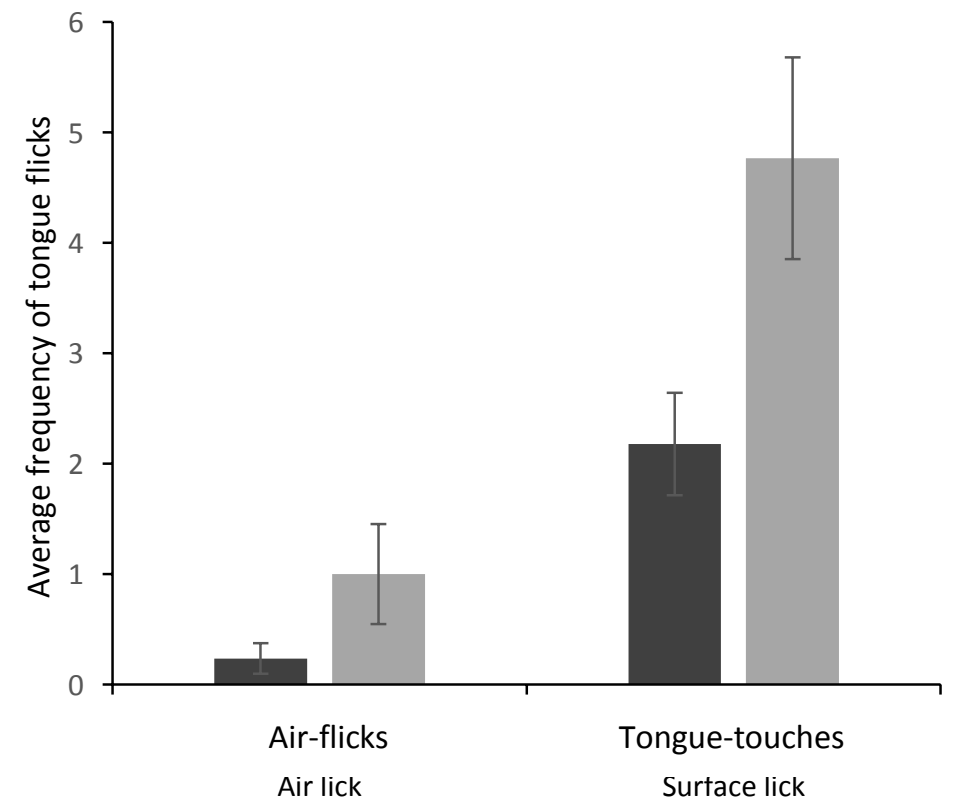

- Familiar

novel 
Figure 1 - The allocation, and adjustments, of groups to environments for habituation and testing. Letters refer to groups of individuals as they moved between test conditions. For example, animals in group 'A' were habituated in Environment 1 and initially tested (Test day 1) in the familiar Environment 1, before being switched to the novel Environment 2 for Test day 2. Whereas, animals in group ' $C$ ' were habituated in Environment 2, initially tested (Test day 1) in the novel Environment 1, before being returned to the familiar Environment 2 for Test day 2.

Figure 2. Tortoises: 2(a) - The average total duration of locomotion (sec) in the familiar and novel environments; 2(b) - The average time taken (sec) to begin locomotion in the familiar and novel environments; 2(c) - The average neck length $(\mathrm{cm})$ in the familiar and novel environments, over the whole test period; $2(\mathrm{~d})$ - The average neck length $(\mathrm{cm})$ measured at 60 second intervals, combined for the two environments (familiar/novel). All data presented as means \pm SE to allow visualisation.

Figure 3. Bearded dragons: 3(a) - The average total duration of locomotion (sec) in the familiar and novel environment; 3(b) - The average time taken (sec) to begin locomotion in the familiar and novel environments; 3(c) - The average frequency of air-flicks and tongue-touches displayed in the familiar and novel environments. All data presented as means \pm SE to allow visualisation. 